\title{
A MÍDIA COMO FERRAMENTA DE PESQUISA: PRODUÇÃO DE SABERES NO COTIDIANO SOBRE A SAÚDE DAS FILHAS DESTE SOLO
}

\author{
Patrícia Flores de Medeiros \\ Neuza Maria de Fátima Guareschi \\ Pontifícia Universidade Católica do Rio Grande do Sul, Porto Alegre, Brasil
}

\begin{abstract}
RESUMO: Este artigo tem como objetivo discutir a mídia como ferramenta de pesquisa a partir de sua produção de saberes no cotidiano e, portanto, relações de poder. Poder aqui entendido como uma rede produtiva que atravessa todo o corpo social e que produz coisas, prazeres, formas de saber e discursos. Focalizamos o programa Fantástico, especificamente, o quadro sobre saúde apresentado pelo Dr. Drauzio Varella, que indica estatísticas sobre a população brasileira e dialoga com mulheres sobre programa de planejamento familiar. Com isso, pretendemos tornar a mídia um campo social demarcando-a como uma evidência, para em seguida, a partir das ferramentas teóricas foucaultianas problematizá-la. Assim, a mídia deixa de ser pensada como uma evidência que naturaliza os objetos dos quais fala e nos permite discuti-la, ou seja, pensá-la como algo que produz aquilo do qual fala.
\end{abstract}

PALAVRAS-CHAVE: Mídia; pesquisa; produção de saberes; modos de subjetivação.

\section{MEDIAAS ARESEARCH TOOL: KNOWLEDGE PRODUCTION IN EVERYDAY LIFE}

ABSTRACT: This article aims at discussing media as a research tool considering its knowledge production in everyday life and, therefore, power relations. Power is understood as a productive network that traverses the whole social body and produces things, pleasures, ways of knowing, and discourses. We have focused on the television program Fantástico, more specifically, on its section dedicated to health, presented by Dr. Drauzio Varella, who presents statistics about the Brazilian population and dialogues with women about family planning programs. We intend to make media as a social field, delimiting it as evidence, so to problematize it using Foucaultian theoretical tools. Thus, media is no longer thought as an evidence that naturalizes the objects it talks about, and lets us discuss it, that is, think of it as something that produces what it talks about.

KEYWORDS: Media; research; knowledge production; modes of subjectiveness.

Você sabe o que se esconde por trás do emaranhado de números e estatísticas sobre o crescimento da população brasileira? O doutor Drauzio Varella começa a discutir um tema que interessa a todo mundo. A todos nós, filhos deste solo. ${ }^{1}$

Nós, filhas deste solo e também pesquisadoras em Psicologia Social, propomo-nos investigar, neste artigo, o que a mídia visibiliza como sendo o sujeito das políticas públicas de saúde, o que se esconde e, ao nosso ver, está na superfície de questões implicadas em uma identidade nacional: a de cidadão brasileiro. Nosso grupo de pesquisa, Estudos Culturais e Modos de Subjetivação, tem desenvolvido investigações na área de políticas públicas de saúde que buscam problematizar os modos como o discurso da mídia produz os sujeitos destas políticas.

Neste campo, Saúde Pública, são produzidos políticas e programas voltados para a população, os quais tomam determinadas configurações, de acordo com as articulações que se estabelecem em cada momento his- tórico, compreendendo formas de subjetivação, estas entendidas como práticas instituídas no cotidiano que forjam determinados modos de relação que as pessoas estabelecem consigo mesmas. Em termos de contribuição para os trabalhos do Grupo de Trabalho Cotidiano e Práticas Sociais, da Associação Nacional de Pós-graduação em Psicologia (ANPPEP), entendemos como pertinente trazermos questões ligadas à saúde pública, mídia e subjetividade.

Ao pesquisar na mídia como a saúde das filhas deste solo - referindo-se ao cotidiano, aos temas das políticas públicas e de cuidados em saúde - têm sido visibilizada pela mídia, através daquilo que pode ser enunciado, vemos como uma forma de discutir como se produzem subjetividades. Para tanto traçamos, num primeiro momento, algumas linhas gerais das formas pelas quais as políticas de saúde pública, direcionada às mulheres, vêm se conformando para terem visibilidade na mídia. Para isto, focalizamos como proposta investigativa não os discursos sobre saúde pública do Ministério da Saúde 
na mídia, mas sim àqueles aos quais a mídia dá visibilidade, isto é, àqueles que ela produz e faz circular.

Convém salientar que estamos trabalhando com a mídia televisiva, mais especificamente com um quadro do programa de televisão Fantástico - sua revista de domingo! O antigo show da vida!, o qual entra nos lares brasileiros de norte a sul nos últimos trinta anos, todos os domingos às 20h30min, fazendo parte do cotidiano dos brasileiros, constituindo-os sujeito de uma cultura midiática.

Para desenvolver essa idéia de cultura midiática nos apoiamos em Hall (1997), para quem a cultura envolve um complexo processo de significação. Segundo o autor "os seres humanos são seres interpretativos, instituidores de sentidos" reforçando assim, que a realidade é uma proposição explicativa; é uma interpretação que institui códigos, sistemas de significação que dão sentido às nossas ações e às ações alheias. A esse conjunto de ações codificadas nomeamos de cultura, ou seja, "contribuem para assegurar que toda a ação social é cultural, que todas as práticas sociais expressam ou comunicam um significado e, neste sentido, são práticas de significação" (Hall, 1997, p. 16).

Desse modo, pode-se colocar também, que a cultura midiática é como práticas sociais que ao forjarem sentidos ganham efeitos de verdade, instituem modos de viver, de ser, de compreender, de explicar a si mesmo e o mundo. Colaborando com essa proposição entendemos que a televisão tornou-se fundamental nos processos de veiculação e produção de significações e de sentidos e na circulação de uma série de valores, concepções e representações relacionadas a um aprendizado cotidiano sobre quem nós somos e o que devemos fazer.

Assim, no momento em que pretendemos visibilizar qual o discurso sobre saúde da mulher o discurso da mídia produz e faz circular é importante esclarecer que os discursos são posicionados aqui como não subjetivos, mas que subjetivam. Desta forma, na medida em que o indivíduo toma para si determinado discurso, considerando-o como legítimo e verdadeiro, passa a modificar e a identificar as prerrogativas desse discurso como suas. Sendo assim, os diferentes discursos que sustentam o cuidado em saúde incidem sobre a vida de mulheres/homens, determinando não somente um modo de viver, como também a experiência que os sujeitos fazem de si mesmos. Esse processo se constitui como um campo de luta entre os modos como os sentidos dos discursos fazem para sermos conhecidos e objetivados e, assim, também os modos de conhecermos e objetivarmos a nós mesmos, através das relações de poder e suas articulações com o saber para constituir um tipo de sujeito (Foucault, 1995).

Nesse sentido, o sujeito é um efeito das relações de poder-saber, assumindo para si determinadas condutas para que outros também o identifiquem como tal: a mu- lher saudável, a cuidadora, a mulher consciente, a cidadã brasileira. Entretanto, afirmar apenas que o sujeito é um efeito deste poder/saber, por si só, ainda é muito pouco. Se o governo da conduta pauta-se em inventar critérios do que deve ser o sujeito, ligando-o, marcando-o e identificando-o a uma identidade, ou a marcas identitárias, como um modelo de ser sujeito, são as relações de poder-saber, então, que tornam possíveis a invenção desses critérios, a sua materialidade por meio de técnicas, procedimentos e práticas, ou seja, o sucesso ou mesmo as resistências a estes.

Na tentativa de investigar essas complexas relações, nos fundamentamos nas contribuições de Michel Foucault, uma vez que grande parte do trabalho desse autor se sustenta na análise da constituição de determinados regimes de verdade e na produção de modos de subjetivação (Foucault, 1995, 1996, 1997, 1998). As ferramentas conceituais foucaultianas utilizadas neste trabalho dizem respeito às noções de poder disciplinar, de biopoder e de artes de governar quando relacionadas às praticas de cuidados de si, a partir de certa forma de normalização, a qual supõe um tipo de ação sobre os corpos, sobre a gestão da vida e de seus processos. Assim, a ênfase da ação não recai tanto sobre a imposição de respeito às regras, mas sobre a produção de comportamentos e a fabricação de subjetividades, de identidades.

Segundo Dreyfus e Rabinow (1995, p. 153), podese dizer que, em praticamente todas as sociedades, se encontra alguma forma de controle sobre o corpo, mas o que parece caracterizar:

. . . o poder disciplinar é o fato de ele dividir o corpo em partes e o treinar, com o objetivo de fazer as partes e o todo funcionarem de forma mais eficiente. Isto acontece de uma forma sutil e contínua, numa rede de micropoderes, incluindo o uso do espaço, do tempo e das práticas cotidianas.

Como diz Foucault (1999), a tecnologia do poder disciplinar tem como objeto a sujeição de corpo do indivíduo, tornando-o dócil, manipulável, enquanto que a tecnologia do biopoder é exercida sobre um corpo, mas não um corpo individual, e sim coletivo. Esse novo corpo político, distinto do individual, a um só tempo instituído pelo biopoder e objeto sobre o qual este se exerce, é a população. Aqui, volta-se para o que a mídia visibiliza enquanto política de saúde da mulher e como isso se coloca estrategicamente para governar práticas sociais de uma determinada população: governar no sentido que Foucault (1996) trabalha, é o de estruturar o eventual campo de ação dos outros.

Para transformar um sujeito em governável, obediente e cumpridor das medidas, não precisa haver, necessariamente, o uso de técnicas de supressão direta, mas estratégias que transformem as características desejá- 
veis em normais e naturais. A medida/padrão que passa a fazer parte naturalmente das práticas do cuidado de saúde de si significa a produção de um tipo de sujeito que regula ou policia a si mesmo. A saúde da mulher pode, assim, ser focalizada como um campo de produção de sujeitos, no qual se compreendem as formas de subjetivação como práticas que se instituem no cotidiano, as quais forjam determinados modos de relação que a mulher passa a estabelecer consigo mesma.

\section{Contextualizando a Saúde da Mulher nas Políticas Públicas}

As questões relativas à saúde das mulheres têm suscitado um crescente interesse, que pode ser observado pela criação de políticas internacionais e nacionais. No caso do nosso país, essas políticas são propostas e desenvolvidas pelo Ministério da Saúde através do Sistema Único de Saúde - SUS. Considerando-se que atualmente as mulheres são a maioria da população brasileira $(50,77 \%)$, estas constituem-se como as principais usuárias do sistema da saúde. Esse fator levou o Governo Federal a instituir 2004 como o Ano da Mulher, propondo a formulação de ações e leis que visam à igualdade e justiça para as mulheres brasileiras. Os principais temas abordados nas ações são: planejamento familiar, morbidade e violência (Brasil, 2004a).

Como ponto de demarcação na construção das políticas públicas de saúde para mulheres, aponta-se a criação do Programa de Assistência Integral à Saúde da Mulher-PAISM (Brasil, 1984), momento em que a saúde da mulher passa a ser problematizada como uma área específica, tornando-se um objeto visível de enunciações. Esse recorte está marcado pela questão da ditadura militar no Brasil e na América Latina, principalmente, na década de 1960, quando ocorre um fechamento nos movimentos sociais que estavam se articulando, motivados por questões econômicas e culturais como o caso de estudantes, sindicatos, camponeses, entre outros. Isso começa a colocar fim aos ideais de liberdade e de uma reforma social enquanto retoma-se a questão do desenvolvimento brasileiro. Passa-se a investir, assim, em um projeto de mito da identidade nacional, impondo a língua portuguesa para todos no país, atividades como juramento à bandeira e reativação do hino nacional como fatores importantes para a afirmação de um Estado-Nação (Nardi, 2005).

Para manter esse projeto era importante que houvesse uma legitimação, o que passou a ocorrer pela implantação de uma série de políticas públicas. Para a criação de políticas na área da saúde foi necessário reunir uma série de cientistas e atores sociais, que nem sempre estavam de acordo com o posicionamento militar. Abriuse, desta forma, espaço para outros modos de produção de saúde: Reforma Sanitária e Saúde Coletiva, além, é claro, da própria área da saúde da mulher. A partir desse momento, torna-se visível a influência dos Novos Movimentos Sociais - que traziam a centralidade da cultura, que como exemplos, podem ser citados, principalmente, o feminismo, questões de identidade racial, o movimento de estudantes e o movimento ecológico.

No final da ditadura militar, o modelo médicoassistencial privativo mostra seu esgotamento a partir da profunda crise econômica do Estado e do realinhamento dos blocos geopolíticos. Como efeito disso, passa a ser gestada uma alternativa para esse modelo, algo que defina um novo padrão de desenvolvimento. Nardi (2005) ressalta que a Reforma Sanitária, ocorrida em plena ditadura militar, surge como um movimento de resistência dos intelectuais ao modelo privado. Dessa maneira, o campo das políticas sociais deriva do movimento da Reforma Sanitária.

É nessa esteira que o PAISM foi lançado no ano de 1983, em um momento de efervescência no Brasil, com atuação de movimentos sociais e da sociedade civil, tendo como criadores três médicos, sendo uma delas mulher e uma socióloga. Tal composição já indicava vontade política de interlocução com o movimento organizado de mulheres. Em linhas gerais, o programa visava ao atendimento integral do corpo das mulheres, não mais como uma série de órgãos isolados. Também a presença da mulher como força de trabalho passa a ser considerada para a definição destas políticas (Osis, 1998). Em termos de políticas públicas de saúde o PAISM, enquanto programa, aponta para a integralidade, que, junto com a universalidade, a equidade, descentralização e a participação como controle social, se transformam nos princípios e diretrizes do Sistema Único de Saúde (SUS) no final da década de 80.

A VIII Conferência Nacional de Saúde, realizada em 1986, representou um movimento de transformação para o quadro da saúde no Brasil, tanto pelo caráter democrático quanto pela dinâmica processual. Essa conferência daria suporte para a elaboração da Constituição Federal de 1988, que incorporou a nova lógica referida pelos princípios da Reforma Sanitária e conceitua a saúde como resultante das políticas sociais e econômicas, como direito de cidadania e dever do Estado e como parte da seguridade social (Mendes, 1999).

Com a Constituição Federal, institucionaliza-se o SUS, que veio a ser regulamentado pelas leis 8.080 , de 1990, e 8.142, de 1990, como provedor das ações e serviços que dizem respeito à saúde definidos na Carta Magna. O SUS delineia-se como alternativa ética e política ao modelo de assistência à saúde, na medida em que se configura como um modelo de atenção integral à saúde da população. O SUS revisa o conceito de saúde até então vigente, definindo saúde como bem comum. O Sistema Único de Saúde é pensado dentro de uma lógica do Esta- 
do moderno, de racionalização de recursos, mas também em uma lógica do Estado social. Assim, por exemplo, diferentemente de como era pensado no Instituto Nacional de Previdência Social (INPS), ou seja, que o direito à saúde seria derivado da relação com o trabalho assalariado, o SUS inverte essa relação. Ele traz o trabalho como direito - e, por isso, a saúde passa a ser para todos e não só para o trabalhador (Nardi, 2005).

Isso implica não apenas nova política de saúde, mas novos modos de a saúde produzir subjetividades por meio de práticas que estabelecem valores, como o de cidadania e de sujeito de direitos, a partir de um dever do Estado. A subjetividade torna-se um eixo de problematizações no campo da Psicologia e, em especial, da Psicologia Social na rede pública, pois o SUS opera com o conceito de cidadania, dever e sujeito de direito, que se conforma juridicamente na Constituição de 1988 (Medeiros, Bernardes \& Guareschi, 2005).

Podemos pensar que ser cidadão e sujeito de direito são formas de subjetividade, formas de viver e de se relacionar consigo e, mesmo forjadas em determinado tempo-espaço, produzem efeitos nas relações entre saúde, cidadania e estado de direito. A saúde, então, passa a ser uma realidade que acontece a partir de determinados processos existenciais ao mesmo tempo em que só é possível a partir de determinadas operações, de certos campos de conhecimento onde ocorrem transportes, traduções, interpretações, isto é, formas de objetivação que, ao darem sentidos a alguns fenômenos, produzem modos de nos relacionarmos conosco.

Desse modo, a saúde da mulher que até a década de 1970 era tomada como objeto das políticas públicas de saúde apenas em sua dimensão procriativa, especialmente no que se refere aos cuidados voltados ao ciclo gravídicopuerperal, passa, a partir de então, ser foco de outras demandas. A saúde da mulher na dimensão procriativa se traduzia na saúde pública em uma ênfase pró-natalista, em que a Medicina embasava a naturalização das diferenças entre os sexos, enfatizando a visão da mulher como mãe (Costa \& Aquino, 2002). De acordo com esses autores, no mesmo período, com o processo de democratização da saúde, constitui-se o cenário ideal para o questionamento do modelo vigente de atenção à saúde das mulheres. A criação do PAISM, em 1983, representou um marco histórico das políticas públicas voltadas às mulheres, e a integralidade passa a ser vista como resultado de uma atitude ética e técnica dos profissionais e uma adequação da estrutura dos serviços de saúde em seu todo.

Desta forma, as mudanças de abordagem nas políticas de saúde da mulher resultaram da convergência de interesses e concepções do movimento sanitário e do movimento feminista, irradiando-se dentro da rede de serviços de saúde um novo pensar e agir sobre a questão da mulher (Costa \& Aquino, 2002). A partir dessa interlocução entre representantes dos movimentos de mulheres e os profissionais da área da saúde, consolidou-se a idéia de atenção integral à saúde da mulher, já presente no PAISM, ou seja, anterior ao SUS. Neste programa, o conceito de integral deveria não só enfatizar a ligação do colo, do útero e das mamas, mas também de outros aspectos não físico-biológicos da vida das mulheres. Ou seja, o atendimento em saúde deveria estar norteado por uma abordagem das mulheres como seres completos, não apenas como partes isoladas de um corpo, mas pessoas que vivem um momento emocional específico e que estão inseridas em um determinado contexto socioeconômico.

Assim, o PAISM foi anunciado como uma abordagem diferenciada de saúde da mulher, a partir do rompimento da visão tradicional, principalmente no âmbito da Medicina, que centralizava o atendimento às mulheres nas questões reprodutivas. O novo programa para a saúde da mulher incluía ações educativas, preventivas, de diagnóstico, tratamento e recuperação, englobando a assistência à mulher em clínica ginecológica, no pré-natal, parto, puerpério, climatério, planejamento familiar, DST, câncer de colo de útero e de mama, além de outras necessidades identificadas a partir do perfil populacional das mulheres (Brasil, 1984).

Contudo, como situaremos adiante neste texto, um desses focos de atenção à saúde da mulher - planejamento familiar - passa a chamar mais atenção, pois se transforma em uma das ações da Política Nacional de Atenção Integral à Saúde da Mulher (PNAISM). Interessante observar que, segundo Osis (1998), durante a década de 70, os movimentos de mulheres caracterizaramse pelo combate à idéia de planejamento familiar como a ação para a diminuição da natalidade e consequentemente, a superação da pobreza, idéia essa presente na atuação da BEMFAM (Sociedade Civil Bem-Estar Familiar no Brasil). Porém, algumas suspeitas também surgiram em relação a uma possível vinculação do PAISM à questão do controle populacional, sobretudo, em vista do momento em que o programa foi lançado, exatamente quando o governo brasileiro sofria pressões externas para adotar uma política demográfica explícita e, justamente, durante uma CPI para investigar o crescimento populacional. Entretanto, esta mesma autora considera que um dos pontos cruciais do PAISM foi, por exemplo, a inclusão da anticoncepção como uma das atividades da assistência integral à saúde da mulher, uma vez que isso se contrapunha às concepções disseminadas pela BEMFAM. Desta maneira, pode-se pensar o PAISM como buscando romper com o enfoque central dos programas de saúde materno-infantil anteriores, que visavam intervir sobre os corpos das mulheres-mães, assegurando que os corpos dos filhos fossem adequados às necessidades de reprodução social. 
Atualmente, as políticas públicas de saúde das mulheres têm sido tomadas como prioridade governamental, formulando-se um documento com princípios e diretrizes para subsidiar as ações na atenção à saúde da mulher no período de 2004-2007 (Brasil, 2004b). Assim, a "Política Nacional de Atenção Integral à Saúde da Mulher - Princípios e Diretrizes" - PNAISM - tem por objetivos: Promover melhoria das condições de vida e saúde das mulheres brasileiras, mediante a garantia de direitos legalmente constituídos e ampliação do acesso aos meios serviços de promoção, prevenção, assistência e recuperação da saúde em todo território brasileiro; Contribuir para a redução da morbidade e mortalidade feminina no Brasil, especialmente por causas evitáveis, em todos os ciclos de vida e nos diversos grupos populacionais, sem discriminação de qualquer espécie; Ampliar, qualificar e humanizar a atenção integral à saúde da mulher no SUS. Os princípios norteadores da proposta são a integralidade e a promoção da saúde, com ênfase nas questões de gênero, buscando consolidar avanços no que se refere às políticas de saúde da mulher. Porém, para o desenvolvimento destes objetivos, curiosamente, esta política estabelece como uma das suas principais ações o Planejamento Familiar.

Ao contextualizarmos, brevemente, a emergência da política pública de saúde para mulher, tentamos descrever o campo de visibilidade e enunciabilidade que vem se constituindo como um instrumento mediante o qual algo passa a ser foco de investimentos. Assim, interrogar sobre as políticas públicas em saúde para a mulher, sobre os discursos que a tornam um objeto de saber-poder não consiste em perguntar somente o que a ciência, preferencialmente a Medicina, diz sobre elas. Implica, também, questionar um conjunto de práticas que torna evidente, no espaço midiático, a mulher como um sujeito a inquirir, a examinar e a controlar, especialmente quando este sujeito mulher passa a ser mostrada e falada como um ponto chave para o controle demográfico da população. Para referenciarmos isto lembramos, por exemplo, as análises de Fischer (2001, p. 588) no que diz respeito às estratégias de linguagem televisiva que indicam uma predominância da mulher, das mais diferentes faixas etárias e condições sociais, como protagonista de inúmeras e diversificadas formas de confissão nas telas da TV: “como sujeitos cada vez mais necessitados de normas e procedimentos para permanentemente cuidarem de si".

\section{A Pesquisa sobre Saúde na Mídia}

Sobre qual saúde a mídia nos faz falar no contemporâneo? Como a mídia produz modos de ser, de pensar sobre esse tema? Como produz os modos de subjetivação a partir das práticas em saúde que visibiliza? Para traba- lharmos essas questões nos detemos nas coisas ditas sobre a saúde da mulher brasileira ao analisarmos no Programa Fantástico - TV Globo, o quadro do Dr. Dráuzio Varella (2005) sobre os "Filhos deste solo". Neste quadro sobre saúde ele se propõe discutir o que está por trás das estatísticas de crescimento da população brasileira situandoa como questões que dizem respeito à saúde pública, mais especificamente, à saúde da mulher brasileira. Assim, a partir de questões sobre a vida e a saúde da mulher, evidencia o tópico do planejamento familiar - que neste caso é tomado como controle das populações fazendo um exercício de raciocínio que retira a questão do controle da natalidade do âmbito do social para colocála em um plano do individual.

Para podermos problematizar essas questões, devemos entender a mídia como uma produção cultural, sendo uma prática discursiva que produz sistemas de significação, produz efeitos específicos nas pessoas, constrói um tipo especial de verdade e diferentes configurações de poder. Desta forma, a mídia deve também passar a ser pensada como uma evidência que naturaliza os objetos dos quais fala-nos, permitindo, assim, poder problematizá-la, ou seja, tomá-la como algo que produz aquilo sobre o qual fala. Neste caso, a mídia nos fala sobre qual cidadão brasileiro deve operar o planejamento familiar: mulheres pobres e com muitos filhos, ou seja, do coletivo para o individual; ou de uma questão social para um corpo individual - sua responsabilidade para com a nação.

As possíveis verdades produzidas pela mídia e que naturalizam os objetos sobre os quais fala, remete-nos a pensar que a verdade deve ser entendida como algo produzido na forma de discursos sobre as coisas do mundo, resultantes de epistemes situadas e datadas e de efeitos de relações de poder. Nos escritos de Foucault (1996), o poder é algo simultaneamente produtivo e repressivo. $\mathrm{O}$ poder deve ser analisado como algo que circula e se exerce em rede, sendo que os indivíduos estão sempre em posição tanto de exercer quanto de sofrer sua ação. Desse modo, o poder não é algo que pertença a um grupo específico e é exercido sobre outro, pois os indivíduos não são alvos inertes do poder, são sempre centros de transmissão. Como podemos perceber dentro dessa perspectiva foucaultiana o poder está em diversos pontos formando redes de relações e tem, principalmente, esse caráter produtivo que dá forma as instituições, objetos e sujeitos. Todavia cabe salientar que esta visão de poder como produtivo não denota necessariamente em uma produção no sentido positivo. Por isso é importante o estudo da cultura no sentido de podermos acompanhar quais os significados que estão sendo produzidos e quais seus efeitos. É nesse sentido que tomamos a mídia como uma produção cultural. 


\section{Situando os Filhos deste Solo no Fantástico}

O programa Fantástico tem como proposta ser " $a$ sua revista eletrônica”, uma mistura de jornalismo e entretenimento para toda a família; está no ar desde 1973, todos os domingos, às 20h30min. O Fantástico tem buscado alternativas criativas para a velha fórmula do programa, com novos apresentadores e atrações. Os quadros incluem ousadias de linguagem, que misturam ficção com noticiário (A. Brasil, 2003). O Fantástico também procura informar e educar o público com o talento do Doutor Drauzio Varella, cujo poder de comunicação e o carinho com que trata ou entrevista seus pacientes são inegáveis. Para o autor mencionado, o programa sempre teve uma forte ligação com os assuntos médicos, mas faltava-lhe um personagem que demonstrasse segurança e credibilidade, que mostrasse ao público que sabe do que está falando - "matérias de saúde na TV não precisam ser necessariamente sensacionalistas e causar pânico no grande público" (A. Brasil, 2003, p. 69).

Foi a partir do ano de 2001 que o Dr. Drauzio Varella passou a fazer parte do programa, com o quadro "E agora, doutor?". A credibilidade à qual Brasil se refere devese ao extenso currículo de Drauzio Varella. Nascido em São Paulo no ano de 1943, foi um dos fundadores do Curso Objetivo, onde lecionou química por muitos anos; dirigiu o serviço de imunologia do Hospital do Câncer (SP); foi pioneiro em tratar o tema da AIDS no Brasil e tem-se dedicado a campanhas nacionais de esclarecimento sobre a doença e sua prevenção. Em 1989, iniciou um trabalho sobre a incidência do vírus HIV na população carcerária da Casa de Detenção do Carandiru, tendo trabalhado como médico voluntário dentro dessa cadeia até sua desativação, em setembro de 2002. Dessa experiência, nasceu seu livro mais importante, Estação Carandiru, transformado em filme em 2003 pelo diretor Hector Babenco. Atualmente, participa regularmente do programa Fantástico, da Rede Globo, apresentando o quadro de orientação de saúde, com destaque para matérias sobre o corpo humano, gravidez, primeiros socorros e combate ao tabagismo (Rovai, 2003).

Na série "Filhos deste solo", Dr. Drauzio Varella (2005) se propõe a discutir o que está por trás das estatísticas sobre o crescimento da população brasileira e a saúde da mulher brasileira. A série é constituída de sete episódios, com uma duração média de 10 minutos, veiculados entre os meses de outubro e novembro de 2005. De forma resumida, os episódios tratam de temas referentes a dados da população brasileira, como estão divididos os números de novos nascimentos e a classe social e idade das mães e de famílias; a situação do atendimento público de saúde para gestantes e mulheres; gestação na adolescência de meninas e a sexualidade de meninos e meninas; o conhecimento e disponibilidade dos métodos anticoncepcionais; a laqueadura e o SUS; o papel do homem no controle de natalidade/vasectomia; direito reprodutivo.

Neste texto, escolhemos o primeiro episódio, com o mesmo título da série, "Filhos deste Solo" (Varella, 2005), para, por meio das ferramentas teóricas foucaultianas - discurso, poder e sujeito - problematizar o campo da mídia, ou seja, discutir aquilo que está sendo proposto como discurso sobre saúde pública que a mídia visibiliza, ou seja, o que ela faz circular. Optamos por trazer algumas falas dos participantes do programa (em itálico), como parte do texto, por entendermos que nossa construção teórica se dá nesse diálogo.

$\mathrm{Na}$ abertura do quadro o Dr. Dráuzio Varella (2005) nos informa sobre a taxa de reposição das populações, os casais devem ter dois filhos, um para substituir o pai e outro a mãe quando estes morrerem, porém: "Entre 1991 e o ano 2000, o número de brasileiros que moram em favelas cresceu três vezes mais do que a população em geral. As causas são a imigração e o aumento do número de filhos." Aqui, ele nos introduz rapidamente na questão oculta das estatísticas: que a população de brasileiros residentes em favelas está aumentando e que este dado tem relação com as políticas de públicas de saúde uma vez que sua próxima questão é: “O Brasil tem um dos mais modernos programas de planejamento familiar do mundo."

Porém, isso indica que o programa de planejamento familiar está muito bem feito, que não há críticas, o que nos coloca em um patamar de igualdade com o primeiro mundo em termos de saúde, sendo esta entendida como sinônimo de planejamento familiar. Ainda, faz-nos direcionar o pensamento para onde reside o problema da saúde no Brasil - já que não está na sua política de cuidados, resta-nos pensar que está na população que deveria estar fazendo seu uso. "A lei é de 1996 e diz que 'O planejamento familiar é direito de todo cidadão e é dever do Estado garantir o acesso à informação, meios, métodos e técnicas para a regulação da fecundidade'”, (Varella, 2005).

Em relação a esta questão de legitimação do direito do cidadão e do dever do Estado como responsável para prover e cuidar da fecundação da população, Weber (2006, p. 87) no diz que: "Ao Estado cumpre fazer chegar ao indivíduo a informação supostamente capaz de prevenir o acontecimento: ao indivíduo, também supostamente informado, caberá assumir os riscos decorrentes de suas ações".

A mídia, como uma tecnologia da informação, subsidia esse processo: o Estado, antes responsável pelos eventos de risco, passa, gradativamente, a dividir com os cidadãos tais riscos. Porém, cabe lembrar que, no caso do planejamento familiar, a mídia não está somen- 
te transmitindo a política do Estado, mas dela se apropriando para produzir uma determinada forma de saber sobre família.

Dr. Dráuzio Varella (2005) nos conta a história de Erinice da Conceição e depois pergunta a ela: "Erenice da Conceição teve nove filhos. Se fosse possível recuar no passado, qual seria o tamanho ideal para a família dela? [Erenice olha para os filhos e responde] Eu acho que uns dois já era suficiente."

Quem fala na mídia? Uma das estratégias de governo utilizadas pela mídia é a articulação de mecanismos que dêem credibilidade diante dos telespectadores, mediante a autoridade dos especialistas que formulam suas sábias e concisas explicações. Nesse caso, precisamos voltar à epígrafe que abre este texto, a qual sugere que o Dr. Dráuzio Varella é quem pode nos explicar o que se esconde atrás da estatística sobre o crescimento da população brasileira, tema de nosso interesse! Como já referenciamos ao citar o currículo do Doutor Dráuzio Varella, este possui conhecimentos, experiências e preocupações sobre as dificuldades das populações carenciadas. Isso pode nos fazer pensar que a mídia tornou esse especialista seu preferido, afirmando para que tipo de pessoas deseja falar, pois o Dr. Dráuzio Varella é dotado das competências necessárias para estabelecer interlocuções com esse tipo de população. Ele está capacitado a ligar estes dois mundos: a academia e o povo, traduzindo para este último o que a ciência sabe sobre ele, que precisa ser esclarecido, referendando-se, assim, a ordem da modernidade. Ou seja, só o especialista pode nos explicar o nosso cotidiano, o que ele propõe como verdadeiro e universal sobre a saúde do brasileiro - que é o controle sobre a família/mulher -, fabricações de identidade nacional que controlam e regulam subjetividades.

É nesse sentido que a mídia pode ser entendida como um campo discursivo, um conjunto de perspectivas, métodos e "verdades" organizados, constituindo práticas com capacidades prescritivas, moldadoras e fixadoras. Como as mulheres/cidadãos brasileiros estão sendo nomeados, posicionados, desejados e descritos? Que espaço teria para Erenice nos explicar por que teve nove filhos? Nesse contexto, podemos identificar sobre quem a mídia fala: a mulher pobre e com muitos filhos que não planejam suas famílias, aumentando o contingente de favelados do Brasil.

Outra estratégia de governo que nos chama atenção é a imputação de carência ou déficit, sendo as deficiências atribuídas a determinados grupos - uma falta de racionalidade, a escola como autoridade de saber. Vemos no trecho abaixo narrado pelo Dr. Dráuzio Varella (2005):

Trinta e oito por cento das crianças de 0 a 14 anos nascem em famílias com renda per capita de até meio salário mínimo. Os números revelam nossa extrema desigualdade. Quanto mais pobre e menos instruída a mãe, mais filhos.

Isso nos faz apontar que essa forma cristalizada como são descritas as mulheres, permite uma relação linear entre escolaridade do sujeito e déficit de raciocínio e entre elevado número de gestações e falta de conhecimento sobre o corpo. Tal fato justificaria a necessidade de esclarecer, ensinar, educar esse grupo deficitário, que aparece triplamente caracterizado: mulher, pobre e ignorante. Como já referimos anteriormente, a saúde pública, campo de cuidado das populações, tem em sua história, entre outros discursos, o de associar o cuidado do corpo feminino com a regulação da pobreza dos países “em desenvolvimento", prática esta ligada ao BEMFAM e que, talvez, neste momento da sociedade, está sendo mostrado e falado pelo discurso da mídia através de outras estratégias discursivas.

\section{Em Termos de Finalização...}

Conforme o entendimento que temos sobre discurso, este não é homogêneo, nem linear, podendo até ser contraditório. Diante disso, uma questão que precisamos apontar é que no desequilíbrio das forças do discurso midiático entre poder e saber, pelo menos duas posições de sujeito podem ser apontadas: a mulher que é visibilizada pela TV e o cidadão/ã que assiste. Em um primeiro momento, o discurso da mídia entra na casa das pessoas com o programa de domingo, tornando as mulheres iguais - cidadãs; em um segundo momento, toma-as como diferentes. As mulheres "pobres" entrevistadas estão lá para ilustrar onde, quando, como e para quem são feitas as políticas de saúde e por que o Brasil não dá certo. Já às outras mulheres, caberia opinar, criticar, cuidar, analisar esse saber, pois estas já deveriam estar subjetivadas por práticas de saúde. Mas a questão é que discurso midiático não é igual a discurso de saúde pública: o que se apresenta aqui é a responsabilização do sujeito mulher pelo planejamento familiar, uma vez que este pode estar representando a organização familiar na sociedade e aquilo que poderia estar faltando para o Brasil dar certo.

Neste sentido ainda, nosso exercício sobre o quadro "Filhos deste solo", entende a mídia como dispositivo pedagógico; particularmente a televisão, no sentido de participar efetivamente da constituição de sujeitos e produções de subjetividades quando, por exemplo, propõe o tema "ser brasileiro e o cuidado de saúde." Ela produz imagens, significações, enfim, saberes que, de alguma forma, se dirigem à "educação" das pessoas, ensinandolhes modos de ser e estar na cultura em que vivem. Neste caso, dirigindo-se ao sujeito-mulher. A mídia toma para 
si o discurso da saúde pública no cuidado com a saúde da mulher, mas, como já referimos anteriormente, produz particularidades nesse discurso, como uma produção própria, dando ênfase ao item planejamento familiar em detrimento a outros aspectos da política que visam uma atenção integral à saúde da mulher. A mídia ensina a mulher que esta deve planejar os filhos que deve ter, o que o Estado deve lhe dar, como seu marido deve ser, enfim, modos de ser mulher.

Assim, operar sobre materiais midiáticos significa analisar textos e imagens, extraindo deles seus enuncia$\operatorname{dos}^{2}-$ discursos que, ao se tornarem regimes de verdade, produzem os modos de viver-, procurando multiplicálos, ampliá-los, para investigar quais modos de viver ali circulam, ou seja, como se propõe ser sujeito no cotidiano. Neste caso, ensinando a mulher como deve se cuidar, como fazer o companheiro usar camisinha, que família deseja ter, qual o número de filhos que pode querer. Definindo o que é certo e errado, o programa vai colocando em prática uma cadeia de validação de enunciados articulados de forma minuciosa para criar e sustentar, com regularidade e suposta legitimidade, um padrão social de referência - o sujeito-mulher desejável, ou seja, a mulher como responsável pela família, pela nação.

Procuramos desta forma, mostrar, mediante um exercício no texto de um quadro do programa Fantástico, algumas reflexões sobre o sujeito-mulher-desejado no discurso midiático, que, ao fazer circular a informação da política de saúde do Estado, escolhe também determinados saberes para isso. A mídia ensina quais são as práticas do cotidiano sobre planejamento familiar e saúde, bem como o modo de como a cidadã-mulher deve se comportar em relação aos seus direitos e deveres para com a sua saúde e a saúde do seu país.

\section{Notas}

1. Pedro Bial, apresentador do Fantástico, na chamada do programa para o quadro do Doutor Drauzio Varella.

2. Para Foucault (2004), o enunciado não constituiria em si uma unidade, pois se encontra na transversalidade das frases, das proposições e dos atos de linguagem. Expressões, como uma frase, uma afirmação, um conjunto de imagens e sons, são atravessadas por enunciados.

\section{Referências}

Brasil, A. (2003, 06 maio). Após sacudida, Fantástico celebra 30 anos. Rio de Janeiro, RJ: Comunique-se. Retirado em 17 nov. 2005, de: http://www.observatoriodaimprensa.com.br/artigos/ asp14052003997.htm

Brasil. Ministério da Saúde. (1984). Assistência integral à saúde da mulher: Bases de ação programática: Vol. 6. Série B. Textos Básicos de Saúde. Brasília, DF: Centro de documentação do Ministério da Saúde.
Brasil. Ministério da Saúde. (2004a). 2004 ano da mulher: Série E. Legislação de Saúde. Brasília, DF: Autor.

Brasil. Ministério da Saúde. (2004b). Política Nacional de Atenção Integral à Saúde da Mulher - Princípios e Diretrizes: Série C. Projetos, Programas e Relatórios. Brasília, DF: Secretaria de Atenção à Saúde.

Costa, A. M., \& Aquino E. A. (2002). Saúde da mulher na Reforma Sanitária Brasileira. In E. Merchán-Hamann, A. M. Costa \& D. Tajer (Eds.), Saúde, eqüidade e gênero: Um desafio para as políticas públicas (pp. 181-202). Brasília, DF: Editora da Universidade de Brasília.

Dreyfus, H., \& Rabinow, P. (1995). Michel Foucault. Uma trajetória filosófica: Para além do estruturalismo e da hermenêutica. São Paulo, SP: Forense Universitária.

Fischer, R. M. B. (2001). Mídia e educação da mulher: Uma discussão teórica sobre modos de enunciar o feminino na TV. Revista Estudos Feministas, 9(2), 586-599.

Foucault, M. (1995). O sujeito e o poder. In D. Dreyfus \& P. Rabinow (Eds.), Michel Foucault. Uma trajetória filosófica: Para além do estruturalismo e da hermenêutica. São Paulo, SP: Forense Universitária.

Foucault, M. (1996). Microfísica do poder. Rio de Janeiro, RJ: Graal.

Foucault, M. (1997). História da sexualidade I - A vontade de saber. Rio de Janeiro, RJ: Graal.

Foucault, M. (1998). História da sexualidade II - O uso dos prazeres. Rio de Janeiro, RJ: Graal.

Foucault, M. (1999). Em defesa da sociedade (M. E. Galvão, Trad.). São Paulo, SP: Martins Fontes.

Foucault, M. (2004). Arqueologia do saber. Rio de Janeiro, RJ: Forense Universitária.

Hall, S. (1997, jul./dez.). A centralidade da cultura: Notas sobre as revoluções do nosso tempo. Educação \& Realidade, Porto Alegre, 22(2), 15-46.

Medeiros, P., Bernardes, A., \& Guareschi, N. (2005, set./dez.). O conceito de saúde e suas implicações nas práticas psicológicas. Psicologia: Teoria e Pesquisa, 21(3), 263-269.

Mendes, E. (1999). Uma agenda para a saúde. São Paulo, SP: Hucitec.

Nardi, H. C. (2005). A naturalização do discurso liberal: Riscos da privatização do público. In M. J. Spink \& P. Spink (Eds.), Práticas cotidianas e a naturalização da desigualdade: Uma semana de notícias nos jornais. São Paulo, SP: Cortez.

Osis, M. J. D. (1998). PAISM: Um marco na abordagem da saúde reprodutiva no Brasil. Cadernos de Saúde Pública, 14(Supl. 1), 25-32.

Rovai, R. (2003, ago.). Suas opiniões são cirúrgicas. Entrevista com Drauzio Varella. Revista Fórum, 3. Retirado em 17 nov. 2005, de: http://www.revistaforum.com.br/Revista/12/ drauzio.htm

Varella, D. (Apresentador). (2005). Filhos deste solo [Série de televisão]. In L. Nascimento (Diretor). Fantástico. A sua revista eletrônica. Rio de Janeiro, RJ: Rede Globo de Televisão. Retirado em dez. 2005, de: http://fantastico.globo.com/

Weber, C. A. T. (2006). Programa de Saúde da Família: Educação $e$ Controle da População. Porto Alegre, RS: AGE.

Patrícia Flores de Medeiros possui graduação e mestrado em Psicologia pela Pontifícia Universidade Católica do Rio Grande do Sul (PUC-RS). Atualmente é doutoranda em Psicologia da PUC-RS. Endereço para 
correspondência: Consultório de Psicologia,

Rua Mostardeiro, 291, conj. 206, Moinhos de Vento,

Porto Alegre, RS,

90040-001. Tel.: (51) 98079272

florespm@terra.com.br

Neuza Maria de Fátima Guareschi possui graduação em Psicologia, mestrado em Psicologia Social e da Personalidade pela Pontifícia Universidade Católica do Rio Grande do Sul (PUC-RS) e doutorado em Educação pela University of Wisconsin-Madison. É professora adjunta da PUC-RS, onde ministra aulas na graduação e pós-graduação (mestrado e doutorado) na Faculdade de

Psicologia e coordena o grupo de pesquisa Estudos Culturais e Modos de Subjetivação. Endereço para correspondência: Pontifícia Universidade Católica do Rio Grande do Sul, Pró-Reitoria de Pesquisa e Pós-Graduação, Faculdade de Psicologia, Avenida Ipiranga, 6681, Partenon, Porto Alegre, RS, 90619-900. Tel.: (51) 3320 3500; Ramal: 3633; Fax: (51) 33203633.

nmguares@pucrs.br

\section{A Mídia como Ferramenta de Pesquisa: Produção de} Saberes no Cotidiano

Patricia Flores de Medeiros e Neuza Maria de Fátima

Guareschi

Recebido: 08/10/2007

$1^{a}$ revisão: $10 / 12 / 2007$

Aceite final: 26/02/2008 